\title{
Citizens' Assemblies and Juries on Climate Change: Lessons from Their Use in Practice
}

\author{
Rebecca Wells
}

Highlights Citizen assemblies and juries (CAJs) must meet generally accepted standards and be citizen-led to genuinely and credibly engage citizens. Agreed implementation and follow-up procedures should be established to ensure CAJs legitimately inform policymaking. CAJs are not a panacea to public participation on climate change and much more needs to be done beyond them.

Keywords Citizen assembly · Citizen jury · Climate change ·

Democratic deliberative process - Citizen engagement

\section{INTRODUCTION}

Globally, 64\% of people believe there is a 'climate emergency' (UNDP, 2021). Since Bristol declared a 'climate emergency' in November 2018, over 300 councils and the UK Parliament have followed suit (Declare A

R. Wells $(\bowtie)$

London School of Economics, London, UK

(C) The Author(s) 2022

C. Howarth et al. (eds.), Addressing the Climate Crisis, https://doi.org/10.1007/978-3-030-79739-3_11 
Climate Emergency, 2020). In response to this climate emergency narrative, many national and local governments have turned to deliberative democratic processes such as citizen assemblies and juries (CAJs) as tools to gauge public opinion to inform their responses to the climate crisis (Mellier-Wilson \& Toy, 2020). Deliberative processes remain relatively marginal, but CAJs on climate change specifically have recently emerged in the UK and abroad (Devaney et al., 2020). CAJs can significantly contribute to engaging more deeply with the public on the climate crisis and creating more inclusive, citizen-driven policymaking and are widely supported in academia and by activist groups such as Extinction Rebellion (XR) (Devaney et al., 2020). However, it is important to critically analyse how CAJs are driving change in practice. To enable learning and improve future CAJs, this chapter identifies how they could be improved by assessing their quality and the impact CAJs have had on policymaking.

Academic and grey literature on the use of CAJs as a method to increase public engagement in climate policymaking was reviewed, followed by a comparative analysis of the reports produced by completed CAJs and the responses of governing bodies in the UK as well at the national level in the UK, Ireland and France. Areas where their use in practice differed from each other and deviated from the literature were identified in order to determine how future processes could be improved to enhance their ability to increase public engagement on climate change.

\section{Are Climate Assemblies and Juries Useful in Tackling Climate Change?}

Tools of deliberative democracy are methods to engage with the public to create a structured dialogue between citizens, experts and politicians in order to help politicians understand public views on different policy approaches, creating more informed political decision-making and thereby increasing the democratic legitimacy of policies (Howarth et al., 2020; Willis, 2020). National governments usually make top-down climate policy decisions with little input from the public and lack a clear sense of the wider public's mandate for climate action. Yet, few attempts have been made to engage the public in the need for, and benefits of, transitioning to a net-zero carbon society (Willis, 2019). Broader and more direct public participation in climate policymaking has been widely advocated as a way to increase the legitimacy and quality of policy decisions, and a failure to do so risks public backlash, such as the 'gilets jaunes' 
protests which emerged in France (Dietz \& Stern, 2008; Kythreotis et al., 2019).

CAJs are deliberative tools to engage with citizens and supplement representative democracy by bringing informed citizens' perspectives into the decision-making process (Smith \& Wales, 2000). The processes are similar but citizen assemblies usually include a representative sample of 50-160 and citizen juries include $12-30$ people in the target population, a group small enough to be genuinely deliberative but large enough to be representative (Bryant, 2019; Roberts \& Escobar, 2015; Goodin \& Dryzek, 2006). An independent oversight panel consisting of key stakeholders oversees the process (Wakeford et al., 2015). Participants receive and cross-examine expert information on a particular issue and deliberate with each other, discussing different perspectives and trade-offs to propose a series of informed and considered recommendations to deal with that issue (Goodin \& Dryzek, 2006; Roberts \& Escobar, 2015; Smith \& Wales, 2000).

CAJs can potentially provide better insight into public opinions on climate change that have been reached in a fair and informed way, allowing citizens to test and discuss a range of approaches to climate action whilst facilitating public support for tough policy decisions by including the concerns and ideas of citizens in policymaking (Willis, 2018; Devaney et al., 2020; Bryant, 2019). However, their use in practice must be analysed to determine the extent to which they achieve and demonstrate these deliberative benefits.

\section{IMPACT ON POLICYMAKING}

CAJs on climate change tend to generate very ambitious recommendations (Willis, 2020). For example, Wilson and Mellier (2020) claim that both the UK and French Climate Assemblies generated far more ambitious policies than politicians have ever proposed. Bryant and Stone (2020) argue that CAJs' biggest impact is to create a strong political platform for action by providing elected representatives with a public mandate on climate change. Often CAJs are followed by increased climate action, such as in Oxford where the council announced over $£ 1$ million additional funding and $£ 18$ million of capital investment to address climate change along with a range of commitments in response to their Citizens Assembly (Oxford City Council, 2019). 
However, the recommendations produced in CAJs often have an advisory role and compete with advice from other groups, making their impact on policymaking difficult to identify (Bryant \& Hall, 2017; Flinders et al., 2015). In most cases, commissioning bodies respond to the recommendations in reference to current policies and claim they will inform an upcoming climate plan. For example, the recommendations produced by the Brent Climate Change Citizens' Assembly (November-December 2019) seem to have had a strong influence over the 2021-2030 Brent Climate Emergency Strategy, which refers to the recommendations throughout (Brent Council, 2020). However, this link is not always obvious. As another example, after the UK Climate Assembly (January-May 2020), the convening parliamentary committees, the government and the Climate Change Committee committed to take the recommendations on board, although it is not clear how (Bouyé, 2020). Dicker (2020) considers the limitations of the process and argues that the UK Climate Assembly could have been improved by having a direct link to legislative, policy and funding decisions as it had no mandate from, or direct link, to government.

The French Climate Assembly (October 2019-June 2020) could have had a large impact as President Macron gave it the power to generate policies that could be enacted either through a national referendum, parliamentary vote or directly through executive orders (Wilson \& Mellier, 2020; O'Grady, 2021). However, almost a year after the Assembly, its members rated the French government's proposed climate and resilience law 3.3 out of 10 for reflecting their recommendations, which suggest that its impact has been far from that which was promised (Climate Home News, 2021). However, recommendations arguably should not be directly implemented, as CAJs are not authorised to govern through democratic processes such as elections. CAJs' lack of democratic validity suggests that they should act as an advisory body complemented by further expertise and evidence-based input (Devaney et al., 2020; O'Grady, 2021). For example, after the Irish Citizens' Assembly, an all-party parliamentary committee was established to respond to the recommendations on climate change. This committee published a report largely endorsing and further developing the Assembly's recommendations, which had a significant role in advising and shaping the development of the Irish government's 2019 Climate Action Plan to Tackle the Climate Breakdown (Devaney et al., 2020). Thus, 
there is a large variation in how CAJs are integrated into policymaking in practice.

There is a need for agreed follow-up and implementation procedures for the recommendations produced by CAJs including a guaranteed response from the commissioning body (Devaney et al., 2020). Ensuring that recommendations from a CAJ are incorporated into the policymaking processes in an appropriate and transparent manner is vital to ensure they are seen as legitimately integrating citizens' views into policymaking (Devaney et al., 2020). Nevertheless, CAJs provide a strong mandate and momentum for climate action which allows policymakers to introduce more drastic policies, as often seen in practice where stronger climate policies are announced following them (O'Grady, 2021).

\section{Are These Tokenistic Processes?}

There is a risk that CAJs are being used as a tokenistic exercise, enabling governing bodies to claim that public opinion has been considered, rather than building a genuine dialogue between them and the public. One key indication of this is that some processes being labelled CAJs do not meet the generally accepted standards for them. For example, the Deputy City Mayor of Leicester (Clarke, 2020) admitted that their Climate Assembly did not qualify as a citizens' assembly as its method of recruitment 'didn't match that of a jury or citizens' assembly' and the process was only one day long (Clarke, 2020). Similarly, the Camden Citizens' Assembly on the Climate Crisis only totalled 12 hours (Cain \& Moore, 2019). Neither of these cases meet generally accepted standards for CAJs which should randomly select participants from the population and be at least 20 hours in length to allow proper learning and deliberation to occur (Cain \& Moore, 2019; Mellier-Wilson \& Toy, 2020). This suggests that some engagement processes are wrongly labelled CAJs because they are currently a trendy engagement method and seen as good politics. For CAJs to truly realise their potential as deliberative processes and be seen as legitimate long-term forms of public engagement on climate change, they must be done rigorously and meet generally accepted standards (Bryant, 2019; O’Grady, 2021).

Those processes being run with a more consultative structure where participants prioritise a pre-prepared list of policy options versus those which allow participants to come up with their own recommendations also run the risk of being used as tokenistic exercises (Bryant \& 
Stone, 2020). For example, the French Climate Assembly was citizenled as it was a political chamber where citizens came up with legislative proposals, which could be directly passed into law (Wilson \& Mellier, 2020). In contrast, the recommendations produced by the UK Climate Assembly were based on predetermined policy options meaning that citizens were not able to shape the agenda, process or come up with their own measures, instead considering those already drafted by government (Wilson \& Mellier, 2020). A more consultative structure may be little more than a short-term consultation for interested parties to give the appearance of public legitimacy to political decisions that have already been made (Wakeford et al., 2015). Therefore, future processes should aim to be citizen-led to allow public concerns to be truly considered in policymaking.

\section{Wider Public Engagement}

CAJs have the potential to ignite wider public debates on climate change. Going back to the example of the French Climate Assembly, it generated a genuine national debate. $70 \%$ of people in France knew of the Assembly, and of those, 64\% considered its work useful to fight against climate change (Resau Action Climat France, 2020). Thus, the Assembly generated a powerful mandate for change but also a movement of people who engaged with the Assembly itself (Wilson \& Mellier, 2020). CAJs run in the UK have largely failed to ignite a wider public debate, often due to budget limitations and integrated planning but also because CAJs are rarely seen as tools which can start a wider public dialogue (Bryant \& Stone, 2020). This is a missed opportunity as CAJs should aim to generate a public debate to increase momentum and hold governing bodies accountable for the recommendations (Wilson \& Mellier, 2020).

However, CAJs are not a panacea for solving issues with public participation and climate policymaking (Smith \& Wales, 2000; Devaney et al., 2020; Flinders et al., 2015). CAJs only represent one form of public engagement and deliberation on climate change, and there are a variety of other communications, education and engagement initiatives available (Devaney et al., 2020). Additionally, public engagement with climate change is required beyond the formal process of CAJs so that people better understand and can help shape low-carbon transformations (Capstick et al., 2020; Devaney et al., 2020). This is demonstrated by the fact that the recommendations produced by almost all CAJs request more 
education and engagement with citizens on climate change. For example, 8 out of the 25 recommendations produced by the Lancaster district Climate Change People's Jury revolved around improving communications, education and council leadership on climate change (Shared Future, 2020). Therefore, whilst CAJs are a positive step towards increasing public engagement on climate change, much more needs to be done to engage with citizens on this issue. CAJs should be used alongside other tools to engage the public and enable them to play a role in climate change policymaking.

\section{CONCLUSION}

Overall, this chapter highlights how the use of CAJs in practice must be critically assessed to allow future CAJs to be improved and have maximum impact on climate action in practice. There is a need for agreed followup and implementation procedures to increase transparency in how CAJs create more citizen-centred policymaking and prevent their use becoming tokenistic. The structure of CAJs varies in practice, impacting the extent to which they truly incorporate citizens' views into the construction of climate policies. Thus, CAJs must be designed carefully to enable their potential benefits to be realised. Furthermore, processes which claim to be CAJs on climate change should meet generally accepted standards to ensure that they represent rigorous deliberative processes and are not tokenistic exercises being used to give the illusion that public opinion has been taken into account in policymaking.

The limitations of CAJs must also be considered when they are being designed and used. For example, CAJs only include a small proportion of the target population, so their representativeness is not a given and their recruitment processes must be robust if their outcomes are to be truly representative.

Nevertheless, CAJs provide an opportunity to gather views on climate change of an informed and representative group of the target population. CAJs can also engage the wider public in climate change debates, an opportunity that future CAJs should seize in order to maximise their impact. However, CAJs only represent one form of citizen engagement and are not a panacea to tackling issues around public engagement on climate change. Thus, whilst their expanding use can increase public engagement on climate change, they cannot be the only mechanism to do so. 


\section{REFERENCES}

Bouyé, M., 2020. Early lessons from France and the UK on the roles of climate citizens' assemblies and legislators to enhance climate action [Online]. Available at: https://www.wfd.org/2020/10/13/early-lessons-from-france-and-theuk-on-the-roles-of-climate-citizens-assemblies-and-legislators-to-enhance-cli mate-action/. Accessed 28 December 2020.

Brent Council. (2020). Brent Climate Emergency Strategy 2021-2030. Brent Council.

Bryant, P. \& Hall, J. (2017). Citizens Jury Literature Review. S.l.: Shared Future. Bryant, P. (2019). Citizens assemblies, citizens' juries and climate change [Online]. Available at: https://sharedfuturecic.org.uk/citizens-assemblies-cit izens-juries-and-climate-change/. Accessed 2 January 2021.

Bryant, P., \& Stone, L. (2020). Climate assemblies and juries: A people powered response to the climate emergency: A guide for local authorities and other bodies. Shared Future.

Cain, L., \& Moore, G. (2019). Evaluation of Camden Council's Citizens' Assembly on the climate crisis. UCL.

Capstick, S., et al. (2020). Climate change citizens' assemblies (CAST Briefing Paper 03). The Centre for Climate Change and Social Transformations (CAST).

Clarke, A. (2020). Making a space for deliberative democracy at Leicester City Council: The Leicester Climate Assembly [Online]. Available at: https:// www.thersa.org/blog/2020/02/making-a-space-for-deliberative-democracyat-leicester-city-council-the-leicester-climate-assembly\#: :text=What $\% 20$ mate rialised $\% 20$ was $\% 20$ the\%20Leicester,'Leicester\%20in\%20a\%20room. Accessed 22 December 2020.

Climate Home News. (2021). French climate bill set for rocky ride after citizens' assembly slams weak ambition [Online]. Available at: https://www.climatech angenews.com $/ 2021 / 03 / 03 /$ french-climate-bill-set-rocky-ride-citizens-ass embly-slams-weak-ambition/. Accessed 8 March 2021.

Declare A Climate Emergency. (2020). List of councils who have declared a climate emergency [Online]. Available at: https://www.climateemergency.uk/blog/ list-of-councils/. Accessed 20 December 2020.

Devaney, L., Torney, D., Brereton, P., \& Coleman, M. (2020). Deepening public engagement on climate change: Lessons from the citizens' assembly. Environmental Protection Agency.

Dicker, S. (2020). Where next for the UK Climate Assembly? [Online]. Available at: https://www.lse.ac.uk/granthaminstitute/news/where-next-for-the-uk-cli mate-assembly/. Accessed 19 December 2020.

Dietz, T., \& Stern, P. C. (2008). Public participation in environmental assessment and decision making [Online]. Available at: https://doi.org/10.3389/fenvs. 2019.00010. Accessed 1 May 2020. 
Flinders, M., et al. (2015). Democracy matters: Lessons from the 2015 citizens' assemblies on English devolution. Democracy Matters.

Goodin, R. E., \& Dryzek, J. S. (2006). Deliberative impacts: The macro-political uptake of mini-publics. Politics \& Society, 34(2), 219-244.

Howarth, C., et al. (2020). Building a social mandate for climate action: Lessons from COVID-19. Environmental and Resource Economics: Special Issue 'Environmental Economics in the Shadow of Coronavirus', Volume in Press.

Kythreotis, A. P., et al. (2019). Citizen social science for more integrative and effective climate action: A science-policy perspective. Frontier Environmental Science.

Mellier-Wilson, C., \& Toy, S. (2020). UK climate change citizens' assemblies \& citizens' juries [Online]. Available at: https://www.involve.org.uk/resources/ case-studies/uk-climate-change-citizens-assemblies-citizens-juries. Accessed 2 January 2021.

Mellier, C., \& Wilson, R. (2020). Getting climate citizens' assemblies right [Online]. Available at: https://carnegieeurope.eu/2020/11/05/getting-cli mate-citizens-assemblies-right-pub-83133. Accessed 10 December 2020.

O'Grady, C. (2021). Power to the people: Nations are turning to citizen assemblies to weigh up climate policies. Science, 370(6516), 518-521.

Oxford City Council. (2019). City Council responds to Oxford citizens' assembly on climate change and outlines 19 million pound climate emergency budget [Online]. Available at: https://www.oxford.gov.uk/news/article/1275/ city_council_responds_to_oxford_citizens_assembly_on_climate_change_ and_outlines_19m_climate_emergency_budget\#: :text=Oxford\%20City $\% 20 \mathrm{C}$ ouncil\%20has\%20responded,Zero\%20Carbon\%20Council\%20and\%20city. Accessed 20 October 2020.

Reseau Action Climat France. (2020). Survey: Gauls not so refractory to climate action [Online]. Available at: https://reseauactionclimat.org/sondage-desgaulois-pas-si-refractaires-a-laction-climatique/. Accessed 7 March 2021.

Roberts, J., \& Escobar, O. (2015). Involving communities in deliberation: A study of three citizens' juries on onshore wind farms in Scotland. ClimateXChange.

Shared Future. (2020). Lancaster district climate change people's jury recommendations. Shared Future; Lancaster City Council.

Smith, G., \& Wales, C. (2000). Citizens juries' and deliberative democracy. Political Studies, 48, 51-65.

UNDP. (2021). The peoples' climate vote [Online]. Available at https://www. undp.org/content/undp/en/home/librarypage/climate-and-disaster-resili ence-/The-Peoples-Climate-Vote-Results.html. Accessed 30 March 2021.

Wakeford, T., Walcon, E., \& Pimbert, M. (2015). Refashioning citizens' juries: Participatory democracy in action. In H. Bradbury-Huang (Ed.), The Sage handbook of action research (pp. 230-247). Sage. 
Willis, R. (2018). Building the political mandate for climate action. London: Green Alliance.

Willis, R. (2019). Citizens' assemblies and citizens' juries: What happens next? [Online]. Available at: https://www.rebeccawillis.co.uk/citizens-assembliesand-citizens-juries-what-happens-next/. Accessed 15 June 2020.

Willis, R. (2020). Too hot to handle? The democratic challenge of climate change. Bristol University Press.

Open Access This chapter is licensed under the terms of the Creative Commons Attribution 4.0 International License (http://creativecommons.org/licenses/ by $/ 4.0 /)$, which permits use, sharing, adaptation, distribution and reproduction in any medium or format, as long as you give appropriate credit to the original author(s) and the source, provide a link to the Creative Commons license and indicate if changes were made.

The images or other third party material in this chapter are included in the chapter's Creative Commons license, unless indicated otherwise in a credit line to the material. If material is not included in the chapter's Creative Commons license and your intended use is not permitted by statutory regulation or exceeds the permitted use, you will need to obtain permission directly from the copyright holder.

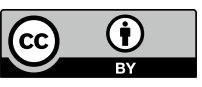

